\title{
Trabajo Social Clínico: conversaciones, voces y ecos que resuenan en la supervisión clínica de la Responsabilidad Penal Adolescente
}

\author{
Clinical Social Work: conversations, voices, and echoes that \\ resonate in the clinical supervision of Adolescent Criminal \\ Responsibility
}
Serviço Social Clínico: conversações, vozes e ecos que ressoam na supervisão clínica da responsabilidade penal de adolescentes

Rodrigo Morales Jiménez*

\begin{abstract}
RESUMEN
El presente documento tiene como objetivo principal generar

Palabras un análisis a partir de una experiencia práctica de supervisión, clave: Trabajo la cual denominaremos "supervisión clínica del Trabajo Social". Durante el transcurso del texto podrán encontrar elementos que contextualizan la intervención profesional en el ámbito de la Responsabilidad Penal Adolescente, principalmente al interior del Programa de Libertad Asistida de la ciudad de Iquique.

El desarrollo de la intervención se enmarca en una supervisión clínica desde un enfoque dialógico colaborativo posmoderno y acompañado de un proceso terapéutico familiar centrado en prácticas narrativas. Los alcances de la supervisión generaron cambios profundos y significativos, no solo en la profesional supervisada,

Social Clínico, supervisión clínica, diálogos colaborativos, terapia narrativa, equipos de reflexión, documentos terapéuticos, construccionismo social.
\end{abstract}

\footnotetext{
* Trabajador Social, Licenciado en Trabajo Social por la Universidad Tecnológica de Chile, Postítulo en Mediación Familiar, Comunitaria y Escolar por el Instituto Argentino de Negociación, Conciliación y Arbitraje. Magíster en Intervención Socio-Jurídica en Familia de la Universidad Andrés Bello de Chile. Coordinador Técnico del Programa de Libertad Asistida Especial, perteneciente a la Corporación Opción en la ciudad de Iquique. Académico del Programa de Magíster en intervención socio-jurídica en familia de la Universidad Andrés Bello de Chile. Docente del Instituto Español de Trabajo Social Clínico. Docente del colectivo de Prácticas Posmodernas. Cofundador de Dialogar-Nos “Encuentros Terapéuticos". rrimoralesj@gmail.com
} 
sino también en el adolescente y su familia, los cuales podrán conocer en la medida que se introduzcan en la lectura del texto.

Se espera que, en el análisis reflexivo, quienes están siendo parte de la lectura de este documento puedan contribuir a otros en sus propias experiencias, y en esas experiencias que se reescriben mientras van leyendo estas líneas. Finalmente, acercarnos a una práctica más humanizadora de las relaciones sociales en contextos de intervención, principalmente de la supervisión clínica del trabajo social en contextos socio-jurídicos.

\section{SUMMARY}

This study's main objective is to generate an analysis based on a practical experience of supervision, which we will call "clinical supervision of Social Work." Throughout this paper, readers will find elements that contextualize the professional intervention in the field of Adolescent Criminal Responsibility, mainly within the Assisted Freedom Program in the city of Iquique.

The development of the intervention is framed in clinical supervision from a postmodern collaborative dialogic approach and accompanied by a family therapeutic process centered on narrative practices. The scope of the supervision generated profound and significant changes in the supervised professional and the adolescent and their family. We hope that in reflective analysis, those who read this document can assist others in their own experiences. Finally, to approach a more humanizing practice of social relations in intervention contexts, mainly clinical supervision of social work in socio-legal contexts.

\section{RESUMO}

O presente estudo tem o objetivo principal de gerar uma análise a partir de uma experiência prática de supervisão, a qual denominaremos "Supervisão Clínica em Serviço Social”. No decorrer do texto, encontrarão elementos que contextualizam a intervenção profissional no campo da responsabilidade penal de adolescentes, principalmente no interior do Programa de Liberdade Assistida na cidade de Iquique.

O desenvolvimento da intervenção compreende uma supervisão clínica desde um enfoque dialógico colaborativo pós-moderno e acompanhado de um processo terapêutico familiar centrado em práticas narrativas. $\mathrm{O}$ alcance da supervisão gerou mudanças profundas e significativas, não apenas na profissional sob supervisão, mas também no adolescente e em sua família, as quais poderão conhecer à medida que avancem na leitura do texto.
Key words: Clinical Social Work, clinical supervision, collaborative dialogues, narrative therapy, reflection teams, therapeutic documents, social constructionism.

Palavras-chave: Serviço Social Clínico, supervisão clínica, diálogos colaborativos, terapia narrativa, equipes de reflexão, documentos terapêuticos, construcionismo social. 
Espera-se que, em uma análise reflexiva, aqueles que estão fazendo parte da leitura deste documento possam contribuir com outros quanto a suas próprias experiências e que essas experiências sejam redefinidas à medida que vão lendo estas linhas. Finalmente, aproximar-nos a uma prática mais humanizadora das relações sociais em contextos de intervenção, principalmente da supervisão clínica no Serviço Social em contextos sociojurídicos. 


\section{Introducción}

El Trabajo Social ha desempeñado, durante largo tiempo, una práctica clínica en la intervención con adolescentes y jóvenes que han conflictuado con el sistema judicial. En este sentido, las instituciones y mecanismos del Estado han desarrollado distintos enfoques, orientaciones y prácticas basadas en evidencias que guían la intervención en estos espacios, principalmente con los adolescentes, jóvenes y sus familias desde una perspectiva psico-socio-educativa.

La intervención y los modelos teóricos que se entrelazan y que actúan como marcos comprensivos de la comisión de delitos de los adolescentes y jóvenes, pertenecen principalmente a la corriente epistemológica cognitivista. En este sentido, uno de los principales modelos para la intervención en la criminología es "creado y desarrollado por los psicólogos canadienses Andrews y James Bonta durante los años 80: El modelo de Riesgo, Necesidad y Responsividad" (Risk-Need-Responsivity) (Valenzuela, 2014, pp. 74-75).

Este enfoque parte de la comprensión de la existencia de distintos factores psicológicos y sociales que pueden incidir en que las personas presenten conflictos con el sistema judicial, y que vuelvan a presentarlos. Es importante destacar que el concepto de "necesidad" se desprende de aquellos factores, constituyéndose como elemento a considerar para ser abordado durante la intervención. Estas necesidades, comúnmente conocidas como "necesidades criminógenas", actúan como elementos concomitantes de la acción delictiva, por lo que su abordaje es fundamental. Finalmente, el concepto de "responsividad" ${ }^{1}$ se traduce como la capacidad de respuesta que presenta la persona durante el proceso de intervención, principalmente su evolución respecto al ajuste de las "conductas desviadas".

Otro elemento teórico para considerar dentro de la intervención que realizan los profesionales con los adolescentes y jóvenes que han conflictuado con el sistema judicial, es el enfoque evolutivo. Este permite ajustar la intervención y su marco comprensivo de acuerdo con

1 El concepto de "responsividad", en inglés responsivity, no presenta una traducción literal al español. El intento de traducción podría ser entendido como la capacidad de respuesta de la persona. 
las etapas de desarrollo y ciclo vital en la que se encuentran los adolescentes y jóvenes. En palabras de Vázquez

presenta los siguientes supuestos: primero, el desarrollo de una secuencia constante; segundo, cada fase del ciclo vital se caracteriza por sucesos que deben ser resueltos de manera satisfactoria para poder avanzar al siguiente; de no ser así, las etapas posteriores evidenciarán niveles de déficit, pudiendo expresarse en desadaptaciones físicas, cognitivas, emocionales y/o sociales y; tercero, cada fase contiene un rasgo dominante, un complejo de rasgos o punto crítico que la distingue de las fases anteriores. (Corporación Opción, 2015, p. 22) $)^{3}$

Es importante considerar que estas intervenciones generan diferencias no solo de la comprensión del fenómeno y la persistencia de la trayectoria delictiva, sino también en las estrategias para abordar los distintos temas con los adolescentes y/o jóvenes; la utilización de estrategias lúdicas para adolescentes de entre 14 y 15 años se diferencia de aquellas que se utilizan para jóvenes sobre los 16 años. Lo anterior no obedece solo a su rango etario, sino al ajuste de sus cogniciones, emociones, pensamientos y acciones respecto de su etapa del ciclo vital.

Existen varias definiciones para hablar del enfoque psico-socioeducativo, algunas que se acercan principalmente al Trabajo Social y a la Psicología Social, en cuanto estudia al sujeto enfatizando en su comportamiento, significantes, valoraciones y las formas de vinculación que presenta dentro de la esfera social. Existen elementos de comprensión, desde una perspectiva sociológica, que aluden al enfoque epistemológico del interaccionismo simbólico, en el que la socialización facilita, a través del lenguaje, la incorporación y respeto de los códigos culturales, normas y representaciones simbólicas en los sujetos.

2 Osvaldo Vázquez Rosssoni, coordinador nacional de proyectos, en al ámbito de justicia juvenil, perteneciente a la Corporación Opción. Presenta publicaciones e investigaciones en el abordaje de la intervención con adolescentes que presentan conductas abusivas "Control para la Agresión Sexual - CAS-R." También coordinador de la publicación del Instrumento corporativo "Sistema Integrado de Evaluación Diferenciada de Adolescentes y Jóvenes -SIED-AJ.

3 Corporación Opción. (2015). Sistema Integrado de Evaluación Diferenciada para Adolescentes y Jóvenes SIED-AJ. Santiago, Chile: Corporación Opción. 
En términos prácticos, la metodología de trabajo se realiza a través de la educación popular, la cual consiste en "utilizar la teoría a partir de la práctica, y no la teoría sobre la práctica” (Bustillos y Vargas, 2001), por lo que resulta elemental que las personas desarrollen una postura activa dentro del aprendizaje, y una colaboración recíproca en estos contextos, con una visión crítica e histórica.

Otra forma de pensar las prácticas terapéuticas, desde un espacio alternativo a las clasificaciones diagnósticas y a la comprensión de los problemas como estructuras (individualizantes y sistémicas), es propuesta bajo una trilogía de enfoques teóricos, los cuales presentan una epistemología posmoderna y postestructuralista, acercándose a un paradigma con base construccionista social radical. A continuación, intentaré aproximarme a una comprensión detallada de cada uno de ellos y su aplicación en la práctica de supervisión clínica en contexto de Responsabilidad Penal Adolescente.

\section{Prácticas narrativas como ética subversiva}

Las prácticas narrativas aparecen como una forma revolucionaria de intervención, que busca superar los intentos de "acceder a la realidad" por una construcción narrativa que los sujetos realizan de sus vidas, nutridas principalmente de sus experiencias. De acuerdo con Bustos (2014), los 3 principios básicos de la terapia narrativa son:

La imposibilidad de acceder a la realidad (Bateson), influencias del poder en las personas (Foucault), y la analogía del texto (Derrida). Generan un espacio de intervención en el cual las historias son las que moldean las vidas de las personas, existiendo historias subyugadas o secundarias, las cuales posibilitan el engrosamiento de la trama dominante. Externalización de los problemas como premisa fundamental. (p. 74)

White y Epston (1980) en Medios Narrativos para Fines Terapéuticos realizan un análisis centrado principalmente en las ideas de Michel Foucault y las relaciones de poder que se establecen en la sociedad. Establecen que el conocimiento y el poder guardan una relación indisoluble, realizando una analogía sobre el relato, el conocimiento y el poder, en la que se hace alusión a la forma en que el lenguaje se constituye como un elemento central del poder a través del concepto "verdad objetiva", aspecto que intenta dominar al ser humano. La ne- 
cesidad de desprenderse del marco epistemológico que sustenta a las ciencias naturales, el cual ha sido adoptado por la comunidad científica, es el inicio de una práctica crítica postestructuralista (White, 2002).

De esta manera, las historias que se cuentan de las personas, y aquellas que se cuentan ellas a sí mismas, moldean sus vidas, aspecto que ejemplifica de manera práctica la relación del conocimiento/ poder.

Ante lo expuesto, la externalización del problema es uno de los principales abordajes terapéuticos, que invita a las personas a separarse de los problemas, comprendiéndolos como entidades externas. Lo anterior permite la comprensión de que los problemas pueden ser analizados como tales, y que los sujetos pueden construir relatos alternativos, "superando la descripción saturada del problema" (White y Epston, 1980). La incorporación de relatos alternativos, según los autores, permite crear nuevas historias a partir de las experiencias de las personas, las cuales pueden ser más amigables para estos y menos determinantes para definir un problema. Se destaca que lo anterior tiene un carácter lineal ${ }^{4}$ y temporal ${ }^{5}$.

Externalizar los problemas permite a las personas atribuir nuevos significados a sus vidas, además de visualizar cuáles han sido los impactos de los problemas para sus vidas. El diálogo colaborativo es parte de la etapa de externalización, en el cual el trabajador social actúa como coautor de los procesos de reflexión y de construcción de los relatos alternativos. Lo anterior, se define por los autores a través de la siguiente frase: "la persona no es el problema, el problema es el problema", como una forma de aseverar que los problemas son parte de un relato culturalmente dominante, que oprime a las personas y que las determina a través de las creencias que éstos atribuyen a su identidad.

La analogía del texto permite visualizar que las personas no se comprenden ni cambian por sus condiciones biológicas y/o naturales,

4 El concepto "lineal" es utilizado como un imaginario en el tiempo, el cual permite avanzar y retroceder sobre una experiencia para volver a contarla y recontarla de distintas maneras.

5 Al referirse a lo temporal, se alude a que cada historia y sus posibilidades de interpretación van a estar situadas a través de un contexto histórico. Los significados que las personas otorgan a sus experiencias pueden ir cambiando en la medida en que el tiempo continúe avanzando; por lo tanto, esos significados tienen una representación temporal. 
sociales o culturales, ya que están íntimamente relacionadas con las historias que otros cuentan o que ellas se cuentan a sí mismas. La historia de los sujetos puede ser reescrita y releída, condensando aquellos elementos que se consideran como "irrelevantes" y que se escapan de aquellos elementos saturados del relato dominante. De esta manera, los conceptos nuevos abren posibilidades terapéuticas distintas, que se definen como "logros aislados", tal como lo expresan los autores, permitiendo a las personas comprender nuevas partes de sus propios relatos. Es importante considerar que la utilización del concepto de "terapia" es abordada por Michel White, quien refiere que el término podría estar siendo mal utilizado, ya que la comprensión de la terapia se da en contextos de "superación de enfermedad". Las prácticas narrativas no comprenden al sujeto y a su relación con el problema desde las patologías, más bien eliminan esos elementos de poder, dedicándose a comprender los significados de las experiencias de los sujetos a través de sus relatos, y de aquellos elementos alternativos a los relatos saturados (White y Epston, 2008).

Las prácticas narrativas centran gran parte de su ejercicio en la creación de documentos terapéuticos, principalmente la escritura de distintos tipos de cartas que otorgan la posibilidad de que las personas puedan liberarse de las opresiones de los relatos saturados. Para White (2002), los documentos terapéuticos presentan un ejercicio terapéutico en sí mismo, el cual permite generar una narración alternativa y otorgar diversas interpretaciones durante el tiempo. Luego de su libro Medios narrativos para fines terapéuticos los autores situaron sus esfuerzos en las nuevas consideraciones sobre los documentos terapéuticos; a través de una investigación informal, White pudo dar cuenta de que estos documentos habían sido profundamente significativos para quienes los escribían, estableciendo que "un buen documento terapéutico equivale a 4,5 sesiones de buena terapia" (White, 2002, p. 202).

\section{Diálogos Colaborativos: una forma de estar con el otro}

El modelo de sistemas de lenguaje en colaboración, desarrollado por Anderson y Goolishian (Alarcón y Schaefer, 2015), presenta una diferencia interesante con las otras terapias de epistemología postestructuralista, principalmente la no existencia de una técnica para su 
realización. Si intentáramos buscar una similitud con otras formas de terapias posmodernas, sería el centrarse en los intentos de solución fallidos e intentos de solución exitosa. Lo cierto es que existen distintos tintes de terapias posmodernas; algunas que se centran en lo ya dicho, las cuales se enmarcan en las narrativas y discursos culturales, y otro camino que lleva a lo que Harlene Anderson definiría como "lo todavía no dicho", principalmente enmarcando su discurso en que la novedad ocurre en el diálogo. Para Anderson (1997, p. 29), el enfoque colaborativo posmoderno presenta las siguientes premisas filosóficas:

1. Los sistemas humanos son sistemas de generación de lenguaje y sentido.

2. Son más formas de acción social que procesos mentales individuales independientes cuando construyen realidad.

3. Una mente individual es un compuesto social y, por lo tanto, el propio ser es un compuesto social, relacional.

4. La realidad, el sentido que nos atribuimos y que atribuimos a otros, a las experiencias y acontecimientos de nuestra vida, son fenómenos interacciónales creados y vivenciados por individuos en una conversación y acción con otros y con nosotros.

5. El lenguaje es generador; da orden y sentido a nuestra vida y a nuestro mundo, y opera como una forma de participación social.

6. El conocimiento es relacional; está inserto en el lenguaje y en nuestras prácticas cotidianas en las que también se genera.

Desde esta perspectiva, podemos entender que la terapia es parte de un proceso conversacional, que se aleja de la pretensión patológica de las ciencias empíricas y comprende que el terapeuta no es un profesional experto que analiza el normal funcionamiento de las relaciones sociales, o que enseña a otros como deberían vivir. El terapeuta debe ser un experto solo en la conversación, en la interacción de las conexiones lingüísticas y de toda acción dialógica, en otras palabras, el buen terapeuta es aquel que realiza buenas preguntas. 
Equipos de reflexión: más allá del secreto

El fundador de los equipos de reflexión es el psiquiatra Tom Andersen (1991), conocido por el libro El equipo reflexivo: diálogos y diálogos sobre diálogos. Este autor y terapeuta ha fundado su metodología de trabajo principalmente en lo que hoy podríamos conocer como una "filosofía participativa y redistributiva del poder", principalmente porque genera la posibilidad de simbolizar al cliente a través de sus palabras, en un contexto de supervisión, así como también incorporar a los supervisores a reflexionar en un espacio de terapia con el terapeuta y con el cliente.

Andersen intenta dejar en claro que los equipos reflexivos no son un "método de trabajo", sino más bien ideas que permiten articular intervenciones sistémicas, desarrollando un profundo respeto por los clientes que participan de estos procesos.

Varios terapeutas han desarrollado equipos reflexivos a partir de la filosofía propuesta por Andersen, la cual se nutre principalmente del principio "las ideas no son mías, son parte de un grupo cambiante de personas que se encuentra ajustado a una cultura determinada, a un contexto histórico y político" (Andersen, 1991). Al ser un modelo sistémico relacional, considera las ideas de Gregory Bateson respecto del cuestionamiento de las verdades universales, de la clínica patológica (Bateson, 1993), construyendo su práctica terapéutica en una práctica centrada en el lenguaje, en la conversación y en las múltiples voces que pueden desarrollar nuevas narrativas.

Michael White también fue uno de los terapeutas que incursionó en los equipos de reflexión, junto a Sylvia London y Harlene Anderson. Ellos centraban sus ideas en los equipos de reflexión basados en la posmodernidad, estableciendo algunas sugerencias para el desarrollo de posibilidades. Para London y Anderson existen algunos elementos que promueven nuevas posibilidades en las supervisiones, principalmente las siguientes:

1. El supervisor enfrenta cada situación como una situación única.

2. El supervisor asume la responsabilidad de crear un clima y un proceso conversacional que invita a la mutualidad y a la colaboración de todos los participantes en la colaboración y en el proceso. 
3. El supervisor permite que el supervisado permanezca en el centro del escenario y que cuente su propia historia de la manera que quiera contarla, sin ser guiado por lo que el supervisor cree que es importante.

4. El supervisor hace preguntas e invita al grupo a hacer preguntas dentro del parámetro del problema, tal y como los describe el supervisado.

5. El supervisor contempla e invita al grupo a contemplar simultáneamente ideas contradictorias.

6. El supervisor fomenta una actitud respetuosa. (London y Rodríguez, 2000, p. 5)

Lo anterior permite establecer una ética de trabajo que se enmarque principalmente en la colaboración, la transparencia y el desarrollo de múltiples historias, contadas a partir de una sola experiencia, ampliando las posibilidades de solución de las personas que participan de manera directa en estos equipos de reflexión.

\section{Acercándonos a la definición del problema}

Las prácticas de intervención profesional en el ámbito de justicia juvenil, así como en otras esferas de la infancia en Chile que se encuentran enmarcadas y supervisadas por el Servicio Nacional de Menores, han sido subyugadas a una relación directa entre el profesional y el desarrollo de recursos administrativos. Esta relación enmarca la comprensión del concepto de "supervisión" principalmente en el seguimiento y fiscalización de la administración de los recursos institucionales, administrativos y financieros, escapando a las necesidades propias adolescentes, jóvenes y sus familias. En otras palabras, se centra en la revisión de documentos que debe contener un expediente, permitiendo evaluar esto como "la intervención correcta". Amaya Ituarte (2012) define la existencia de tres tipos de supervisiones: supervisión formativa, que dice relación con la comprensión de que existe un experto y un no experto, siendo el primero quien debe revisar y enseñar al supervisado; supervisión administrativa, que se basa principalmente en una revisión de documentos y protocolos que deben existir en un determinado expediente y, finalmente, supervisión clínica, entendida como un proceso de conversación donde no existe 
un experto, sino más bien dos personas que construyen a partir de una experiencia, ajustada a los principios disciplinares. Lo anterior no solo ha dificultado el ejercicio de quienes realizan intervención directa con los adolescentes y jóvenes en estos espacios, sino también de quienes cumplen el rol de supervisar y acompañar, de manera directa, la intervención que realizan los profesionales, estableciéndose métodos de supervisión que oscilan principalmente entre el tipo formativo y el administrativo.

El modelo neoliberal, basado en competencias y en la ética de la productividad, en el cual se enmarca la intervención en el ámbito de infancia y justicia juvenil, ha transformado lentamente al profesional, acompañante y encargado de supervisar las prácticas de intervención, en un agente experto en la materia, trascendiendo de una supervisión clínica a una que oscila entre la esfera formativa y la administrativa. Lo anterior no solo ha generado criterios inflexibles respecto a lo que "debería contener una intervención", sino que también ha causado dificultades y distintas emociones en aquellos que deben ser supervisados de manera constante, principalmente sensaciones y sentimientos como estrés, angustia, ansiedad, molestia, agotamiento, entre otros elementos que facilitan el desarrollo de burnout en los terapeutas (White, 2002).

Dado lo anterior nos preguntamos, ¿para qué es necesaria una supervisión clínica en el campo de la intervención con adolescentes que han presentado conflictos con el sistema judicial y social? Los avances en las disciplinas como Trabajo Social, Psicoterapia, Psicología, Neurociencias, entre otras, han considerado que las intervenciones destinadas a aliviar el dolor del otro requieren de una resonancia entre el terapeuta y la persona, en la que ambos se conectan en una acción dialógica que contempla la exploración de las experiencias, historias $\mathrm{y}$ vivencias que se encuentran marcadas por el dolor y el sufrimiento. Estas vivencias han sido traducidas como conflictos psicosociales que se expresan en un malestar psicosocial de la persona y otros sistemas humanos. Respecto de esto, el Trabajo Social con la perspectiva "la persona en situación” (Dorfman 1996) da cuenta de interrelaciones. En los contextos en los que se ejerce prácticas clínicas del trabajo social, principalmente en la justicia juvenil, se encuentran los jóvenes cobijados por la hostilidad, el dolor, la vulneración de derechos y la 
exclusión social, afectando también a los profesionales que, de manera cotidiana, deben acompañar los senderos que transitan las personas que forman parte de estos programas, constituyéndose así, la práctica clínica, en una fuente de estrés en sí misma, lo cual es relevante y debe ser enfrentado (Ituarte, 2002).

Lo anterior nos permite comprender que el alivio del malestar psicosocial no solo es el objetivo del profesional, sino que también el de la supervisión clínica, comprendiendo que el profesional no es un objeto inerte de la intervención, es parte de un proceso de encuentro y conversación entre dos o más personas. La personalidad del profesional influye necesariamente en el proceso terapéutico. A modo de ejemplo, tal y como la cantidad adecuada de sal otorga un sabor distinto a la preparación de una comida. Lo verdaderamente importante no es generar una diferencia respecto a las emociones de la persona y el terapeuta, ya que el ejercicio terapéutico en sí mismo se encuentra centrado en la exploración de la naturaleza entre la subjetividad individual o la intersubjetividad (Szmulewicz, 2013, p. 63).

Para Amaya Ituarte (2002), la supervisión clínica presenta cuatro importantes objetivos por los cuales debería realizarse:

- Apoyar al trabajador social ante las situaciones de estrés que produce el trabajo clínico.

- Ayudarle a analizar, comprender y modificar aquellos aspectos de la relación que podrían tener una incidencia negativa en el tratamiento psicosocial del cliente.

- Ofrecerle apoyo necesario para asegurar que el cliente recibe la atención más adecuada a su situación, con los menores costes posibles (personales, profesionales institucionales, económicos, etc.).

- Analizar los aspectos éticos presentes en cada situación, apoyando al trabajador social en la aplicación de los principios deontológicos de la profesión. (p. 55)

No obstante, existen dificultades para realizar una práctica de supervisión clínica ajustada a la ética de la colaboración, en un proceso de intervención enmarcado en el ámbito de justicia penal adolescente, ya que esta área concibe los procesos terapéuticos desde modelos estructurales sistémicos e internalizantes, tal como el modelo cognitivo conductual. A pesar de aquello, siempre hay grietas que se pueden 
aprovechar para introducir otras lecturas y así reducir las influencias de las micropolíticas dominantes sobre el hacer intervenciones que se ajustan al statu quo (Pakman, 1997).

Proceso de participación o injerencia del profesional y cliente, paciente o caso en la intervención

El profesional, Trabajador Social, cumple la función de realizar una supervisión clínica a otra profesional (Trabajadora Social), que realiza intervención con un adolescente sancionado a 541 días de libertad asistida, por el delito de robo con violencia.

El rol del profesional, que actúa como un supervisor clínico de los procesos de intervención al interior del programa de libertad asistida, permite incorporar prácticas y metodologías alternativas a las que se encuentran establecidas para la intervención. En este sentido, la invitación al desarrollo de una intervención colaborativa, que nace desde el encuentro entre dos profesionales que establecen conversaciones respecto de la vida de un tercero, que se encuentra presente a través de las experiencias relatadas por el terapeuta, permite superar la dicotomía del supervisado "sabe/no sabe" respecto a lo que conocemos por intervención y encontrarnos en un acontecer clínico que beneficia al adolescente y/o joven y al terapeuta.

La intervención se enmarca principalmente en la ética colaborativa de intervención, pasando desde un enfoque estructural a uno postestructuralista, que combina las prácticas narrativas, los diálogos colaborativos y los equipos de reflexión como elementos teóricos, epistemológicos y metodológicos que pavimentan la supervisión del caso.

\section{Acciones a realizar}

- Realizar supervisión con programación trimestral del caso.

- Realizar supervisión clínica adicional, cuando la profesional la requiera, a través de estrategias conversacionales colaborativas.

- Reflexionar respecto de la construcción de objetivos de intervención trimestral, proponiendo un trabajo centrado en un abordaje terapéutico desde las prácticas narrativas.

- Reflexionar sobre las prácticas de intervención (métodos y estrategias utilizados por la profesional). 
- Reconocer dificultades y obstaculizadores que enmarcan la intervención.

- Reconocer oportunidades y fortalezas para la intervención profesional.

- Acompañar en intervenciones directas con el joven cuando la profesional lo requiera.

\section{Formulación de hipótesis de intervención}

- El desarrollo de una supervisión clínica, centrada en enfoques colaborativos posmodernos, disminuye la ansiedad de los profesionales al participar de las instancias de supervisión de casos.

- Posicionarse como profesional experto mecaniza la intervención, dificultando la aparición de nuevas posibilidades de conversación en la terapia.

- El empleo de estrategias conversacionales de carácter colaborativo favorecerá el desarrollo de alianzas terapéuticas entre la profesional y el adolescente.

- Las construcciones de documentos terapéuticos desde un enfoque narrativo favorecerán directamente la adhesión del adolescente a su proceso de intervención.

- La ética de la intervención colaborativa genera mayor motivación en los profesionales para comprometerse en los procesos de intervención.

Respecto de la intervención, es necesario indicar que se enmarca en un contexto socio-jurídico, principalmente por la existencia de una ley penal que mandata las acciones que los programas y equipos profesionales desarrollan con los adolescentes y jóvenes que se encuentran cumpliendo una sanción. En este sentido, el principal obstáculo visualizado por la profesional supervisada es el carácter de obligatoriedad; por lo tanto, la primera idea que debemos considerar al momento de recibir a una persona que dice no tener problemas es que efectivamente no tenga ningún problema (Alarcón y Schaefer, 2015).

En los contextos socio-jurídicos, y especialmente en la responsabilidad penal adolescente, no existe la figura de demanda espontánea para la intervención, ya que todos los jóvenes que asisten a los programas presentan como causa inicial la comisión de algún delito. 
En este sentido, los jóvenes no asisten a un proceso de terapia porque así lo deseen, sino más bien porque la fuerza del Estado, en su carácter regulador y punitivo, sanciona a los adolescentes y jóvenes a cumplir con un programa de reinserción social, lo cual es entendido en palabras más simples como una terapia obligada. En este contexto, el esfuerzo profesional inicial es llevar la conversación terapéutica a un punto de encuentro entre la profesional y el adolescente, en el cual puedan construir un camino para disolver el problema. Harry Goolishian reemplaza el término "resolver un problema" por "disolver un problema", principalmente por la desaparición en el lenguaje. Para el construccionismo social, los sistemas con los que trabajamos existen solo en el lenguaje y, por lo tanto, los problemas existen solo en el lenguaje. El objetivo de la terapia no es encontrar soluciones a los problemas, sino participar en un proceso que desarrolle un lenguaje en el que el problema ya no existe (Goolishian, citado en Anderson, 1997).

En este sentido, la alianza terapéutica, o vínculo terapéutico, presenta, según Harlene Anderson, la necesidad de interesarse por "aquello no dicho y lo todavía no dicho". Principalmente eso se traduce en poner atención a lo que la persona, en este caso el adolescente, quiere contar de sí mismo, aquello que a él le interesa que las personas conozcan sobre él, y no establecer una relación desequilbrada respecto del uso del poder en la sesión. Para Anderson (1997), las personas logran percibir cuando los terapeutas preguntan aquello que les interesa como profesionales, y dejan de escuchar realmente a la persona: "aquello no dicho y lo todavia no dicho" (p. 199).

Al hablar de supervisión, no nos referimos a cualquier tipo, intentamos totalmente superar los tipos de supervisión formativa y/o administrativa, e intentamos situarnos en una supervisión clínica, sin perder de vista una posición ética y metodológicamente enmarcada en el ejercicio disciplinar del Trabajo Social. En este sentido, Ituarte (2012) refiere lo siguiente:

La supervisión clínica tiene unas características que la diferencian de otras formas de supervisión, como la formativa o de tipo administrativo. En la supervisión clínica no hay un profesional, el supervisor, que es el que sabe, y otro profesional, supervisado, que es quien hace. Ambos saben y hacen cosas distintas, aunque complementarias y dirigidas a un objetivo en común: ayudar a que el 
trabajador social tenga una práctica más coherente, sólidamente fundamentada, adecuada a la situación real del cliente (individuo, pareja, familia, grupo), acorde a los principios éticos y a la deontología profesional y que, además, resulte más satisfactoria y lo menos onerosa posible para todos los intervinientes en la situación. (p. 194)

Durante la escritura del documento, hemos hablado del ejercicio de supervisión clínica ${ }^{6}$; sin embargo, prefiero adherirme al concepto, utilizado por Michael White, de "co-visión". Si bien la supervisión habla principalmente de la relación entre el interventor y/o terapeuta, el trabajo que realiza y el supervisor; como encargado de brindar asesoramiento, este no intenta establecer los conocimientos del supervisor por sobre los del ejectutor directo de la práctica interventiva. White (2012) utiliza la siguiente descripción:

El término co-visión ha sido propuesto como alternativa a la supervisión. Este término es propuesto con la expectativa de que contribuirá a la estructuración de prácticas que proporcionen un antídoto contra la jerarquía del conocimiento y las relaciones de poder inflexibles que están asociadas al concepto de supervisión. En efecto, co-visión ofrece una descripción igualitaria de la relación entre los terapeutas, que consultan acerca de su trabajo, y los consultores, que responden a estas consultas; una descripción que desafía la jerarquía de conocimientos que está asociada al concepto de supervisión. (p. 188)

La supervisión clínica, en este contexto y enmarcada en esta metodología, aparece como una forma de reflexionar respecto de nuestras ideas de control social, y acerca de ampliar el horizonte de posibilidades de conversación en la intervención socio-jurídica, a un punto en que el profesional abandone el lugar de experto y se posicione como un colaborador del experto, en este caso el interventor ${ }^{7}$, para desarrollar un lenguaje alternativo a los discursos saturados.

6 Se utiliza el concepto de "supervisión clínica" solo para efectos de lectura, ya que la metodología de trabajo se encuentra basada en un enfoque colaborativo, intentando superar la relación de poder de la supervisión.

7 La referencia de interventor "experto" obedece a una comprensión ética de los enfoques postestructuralistas, los cuales comprenden que no existe un acceso privilegiado a la realidad. Los expertos, en sus experiencias y sus vidas, son los consultantes, en este 
En este caso, la intervención centrada en el proceso de supervisión presenta la finalidad de deconstruir el pensamiento saturado de la profesional y establecer nuevas posibilidades para la intervención.

Elaboración del proceso de evaluación de la intervención

\begin{tabular}{ll}
\hline Cantidad de supervisiones & Seis \\
\hline Frecuencia de reuniones & $\begin{array}{l}\text { Al inicio se realizaron supervisiones } \\
\text { semanales (dos), luego mensuales } \\
\text { (cuatro). }\end{array}$ \\
\hline $\begin{array}{l}\text { Cantidad de documentos } \\
\text { terapéuticos elaborados }\end{array}$ & Cuatro \\
\hline Primer documento & Carta de hijo a madre \\
\hline Segundo documento & Carta de madre a hijo \\
\hline Tercer documento & Carta del adolescente para él mismo \\
\hline Cuarto documento & Carta de terapeuta a supervisor \\
\hline
\end{tabular}

\section{De la supervisión misma}

Durante las primeras supervisiones se logró apreciar dificultades para desarrollar vinculación con el adolescente. La profesional refería en varias oportunidades sentirse agotada, principalmente porque consideraba que el joven se mantenía precontemplativo respecto de la posibilidad de un cambio en las "conductas delictivas". De igual manera, la delegada visualizaba factores de riesgos presentes, tales como la vinculación a grupo de pares con conductas criminales, consumo dependiente de cannabis sativa (marihuana), dificultades en las relaciones familiares, elementos que se traducían en una escasa supervisión parental y deserción educativa. Es importante indicar que la idea inicial de la supervisión, desde la perspectiva de la delegada, era poder validar su juicio profesional, el cual estaba fundado en una conducta del joven, altamente refractaria a las normas del funcionamiento del programa, aludiendo en varias oportunidades a la necesidad de solicitar un quebrantamiento de la sanción por una de mayor gravedad. Ante lo anterior, White (2002) hace alusión al término "deconstrucción", como una necesidad de que los equipos de reflexión puedan ayudarse a "deconstruir" sus propias respuestas:

caso los profesionales delegados de caso que participan de las intervenciones en Responsabilidad Penal Adolescente. 
En el contexto terapéutico, la distribución del poder siempre es desigual, independientemente de las medidas que tomen los terapeutas para evitarlo (...) Las posibilidades de que esta distribución desigual del poder descalifique y cosifique a las personas es mayor cuando se trata de un equipo. Por eso es importante que se tomen medidas para contrarrestar los posibles efectos nocivos de este desequilibrio de poder, para reducir las posibilidades de daño. (White, 2002, p. 190)

En este sentido, el relato saturado de la profesional se puede apreciar en la escasa visualización de cambio respecto de las conductas del joven, y la necesidad de generar mayor control social y punitivo como forma de respuesta ante esta saturación.

Durante las siguientes supervisiones situamos la conversación en explorar. ¿De dónde nacían las ideas de que el control social podía modificar las conductas de las personas? Preguntándonos si efectivamente creíamos que las personas podían reflexionar profundamente, por medio de la coerción del sistema, y así "comprender que estaban errados en sus conductas y quisieran modificarlas para adaptarse a lo que conocemos como norma judicial". A raíz de lo anterior, logramos recordar el concepto construido del "panóptico" y dar cuenta de la existencia de una formación basada en el control social, desde el Estado, las familias y los organismos educacionales, y de la repercusión de este eje de control social desde el pedestal profesional. La necesidad de control social no solo ha sido descrita por Michel Foucault en sus distintas investigaciones, sino también por Jacques Danzelot en Policía de las Familias. En palabras de Dallorso (2000):

Para ello recurre a un abordaje genealógico heredero de los trabajos de Foucault. En este sentido, Donzelot aborda a la familia desplazándose de los acercamientos institucionalistas y privilegiando, en cambio, un punto de vista global en que se pueda reconstituir toda una red de alianzas, comunicaciones, puntos de apoyo; en otras palabras, adopta el punto de vista global de la tecnología de poder. De este modo, la familia emerge como el resultado de un complejo juego de estrategias y fuerzas que interactúan a partir de múltiples puntos dentro y fuera de la familia. (p. 167)

En la medida en que se continúa con las sesiones de supervisión, vamos acercándonos a una ética colaborativa de la conversación, en 
el que iniciamos preguntándonos: ¿cómo podríamos acercarnos al adolescente, en una conversación que abandonara esa necesidad de validar los propios saberes como terapeuta, y a una necesidad de ser informada sobre aquello que realmente la persona quisiera contar de sí mismo: "usted me escuchó. Oyó exactamente lo que dije. Lo único que quería realmente es que alguien me oyera" (Anderson, 1997, p. 208). Logramos comprender que lo realmente importante era aquello que jamás había sido escuchado, aquello no preguntado, lo que Harlene Anderson definiría como "aquello no dicho, y todavía no dicho", o lo que en otra de sus metáforas intenta definir: "Para alcanzar lo que no sabes, deber seguir el camino de la ignorancia”.

Luego de haber realizado las intervenciones durante un mes, la profesional supervisada logra vincularse con el joven. A continuación revelo un extracto de la conversación durante una de las supervisiones, en la que la delegada de caso cuenta lo que significó desprenderse del control y desarrollar una ética colaborativa, en este sentido, para la profesional supervisada:

Me sirvió preguntar lo que desconocía, me sirvió realmente interesarme por él, y para eso tuve que centrarme realmente en él. Creo que él lo percibió y así pudo abrirse. Me pudo contar de sus experiencias de violencia intrafamiliar, de cómo el veía que a su madre la golpeaban. Fue difícil y duro escuchar su historia, y lo que aún creía, y me di cuenta de que se encuentra viviendo una etapa muy difícil. Él percibe que su madre volvió con su papá porque no tienen dinero, y siente que lo está haciendo para que él y sus hermanos puedan comer todos los días. Jamás se lo ha preguntado, aún no se atreve a hacerlo, porque refiere que no tiene tanta confianza con su mamá para preguntarle, pero él lo siente así, y está muy preocupado porque no quiere volver a vivir nuevamente escenas de maltrato para su madre. (González, 2018)

Buscamos una forma de ayudar al adolescente, pero nos dimos cuenta de que, para continuar en una ética colaborativa, no éramos nosotros quienes deberíamos decidirlo, era él mismo quien debía decidir si realmente necesitaba ayuda y, más aún, la forma en cómo debería desarrollarse. En este sentido, no me refiero a negar el ofrecimiento de ciertas estrategias que los profesionales han entrenado y que mantienen a disposición de las intervenciones. Si el adolescente 
quisiera consultar por algunas, es algo que necesariamente realizaríamos.

En la medida en que la delegada continuaba trabajando desde la colaboración con el adolescente, éste logro encontrar en las sesiones de intervención un espacio de diálogo, de contención y de ayuda. Camila propuso trabajar, mediante cartas terapéuticas, las experiencias del adolescente en su infancia, transmitirlas a ese público que se constituía como importante para él (su madre). Boris estuvo de acuerdo y consideró que sería una gran forma de expresar sus sentimientos, reescribir su experiencia y transmitirle sus miedos actuales a su madre. A continuación se muestra la carta escrita por el adolescente, al cual solo hemos llamado Boris como una forma de resguardar su identidad:

¡Hola mamá!

En esta carta quería agradecerte por todo lo que has hecho por nosotros te pido perdón por todas esas veces que me porte mal y tuviste que ir a buscarme a la comisaria tu eres la única que a estado en las buenas y en las malas a veces siento que mi papa no se merece estar contigo después de tantos años que nos hizo sufrir, yo creo que entiendes pero tienes miedo de morirte y por eso lo aceptas me duele que ya no confies en mi y que para que no me meta en problemas no quieras trabajar hay papa aparece y tu lo aceptas porque sino no comeríamos. Como me gustaría tener un trabajo estable para poder mantenerte en la casa para que no dependiéramos de mi padre, te amo mucho y lo siento por hacerte pasar tanta rabia a veces me siento triste y sin querer le ago daño a la persona que mas amo. Te prometo que este año aprobare y saldré adelante.

Durante la supervisión siguiente, conversamos con Camila sobre qué le había parecido esta experiencia. A continuación, un breve relato de lo referido por la delegada:

Boris estaba muy emocionado al escribir la carta, lo noté tan concentrado que no fue necesario ayudarlo. Cuando terminó de escribir le pregunté cómo se había sentido, y me contó que esta modalidad le había acomodado mucho, ya que se define como alguien al que le cuesta expresar las cosas "conversando". Mi intención era saber si para él había sido difícil escribir la carta, en términos emocionales, a lo que me refirió que sí, pero que mientras escribía se había dado 
cuenta de algunas cosas, como por ejemplo del inmenso amor que tenía por su madre, de lo importante que ella ha sido en su vida y de todas las veces que ha estado presente. También se dio cuenta que ha sido un sobreviviente, que ha decidido algunos caminos que lo alejan de aquello que quiere lograr, y esa es una de las cosas que le escribe a su madre, la promesa de que aprobará el colegio. La verdad es que, en lo personal, es la primera vez que trabajo en prácticas narrativas, solo las conocíahora que estábamos en supervisión, y debo decir que al principio no me imaginé a Boris escribiendo una carta, pero a medida que lo veía escribir, me pude dar cuenta que hay muchas cosas a las que jamás podré acceder, porque son parte de él, de sus experiencias y de sus historias, $y$, por lo tanto, era el único capaz de poder contarlas de la manera que él quería. Me agradó mucho esta forma de trabajo y creo que sería necesario preguntarle a Boris si quiere entregarle esta carta a su madre. (González, 2018)

En la medida avanzaban las supervisiones y las intervenciones nos alejábamos cada vez más de las terapias estructuralistas, de los enfoques cognitivos conductuales, así como de la criminología. Nos empezamos a dar cuenta de que lo importante no era verificar cuál era el riesgo de "reincidencia delictiva" que "tenía el adolescente", visualizado como un objeto, como un fruto de las teorías, o como algo inerte que da respuesta a una escala construida por saberes científicos a los cuales Boris jamás había podido aportar, o por lo menos no de manera voluntaria. Camila se interesó por aquello por lo que el Derecho, las ciencias exactas y el empirismo de las ciencias sociales no se habían logrado interesar, se interesó por Boris.

Se le propuso al adolescente la posibilidad de poder entregar la carta que él había redactado a su madre, a lo que inmediatamente contestó con un sí, aunque sentía que aún no se encontraba preparado para poder participar de esa sesión, por lo que pidió a Camila que fuera ella quien hiciera esa entrega. La delegada invitó a la madre de Boris a participar de una sesión, comentándole que tenía algo muy importante en su poder, elaborado por su hijo, y que éste había pedido especialmente que fuera entregado en sus manos. De esta manera se logró realizar la sesión con la madre del adolescente.

Durante la siguiente supervisión exploramos con la profesional supervisada los resultados de la sesión que había tenido con la madre 
de Boris. Principalmente reflexionamos acerca de cómo había logrado que la madre de Boris participara de la sesión y cuál había sido la percepción de la delegada sobre la sesión con la madre del adolescente. En palabras de Camila durante la supervisión, intentaremos acercarnos hacia aquellas respuestas.

Creo que lo más importante fue romper con las "típicas" llamadas telefónicas para citar a los adultos responsables a un programa. Me logré dar cuenta que esto de "desaprender" también sirve para ampliar las posibilidades con las personas; por ejemplo, lo que hice en esa llamada fue olvidar que este es un programa de sanción, incluso romper con el concepto de "citar a las personas", me pareció más pertinente utilizar la palabra "invitación", porque fue justamente eso lo que hice, invitarla a que conociera algo que yo tenía, pero que había sido elaborado por su hijo, y sentí claramente una diferencia en su voz. Quizás fue mi percepción, pero sentí que ella vendría no porque la estuviera obligando, sino porque ella quería conocer lo que su hijo había elaborado. (González, 2018)

En esta conversación nos dimos cuenta con Camila de que se había posicionado, durante varias sesiones, en una ética colaborativa posmoderna, y que se encontraba trabajando desde lo que Harlene Anderson (1997) definiría como una responsabilidad compartida:

La responsabilidad es un valor de nuestra cultura. Queremos que cada uno sea responsable y dé cuenta de sí, ante sí mismo y los demás. Sin embargo, los terapeutas no siempre creamos los contextos y las relaciones que hacen posible y estimulan la responsabilidad. Estamos entrenados para participar en conversaciones desiguales, para quitarle responsabilidad al cliente, para ser expertos en cómo la gente debiera vivir su vida, en las narrativas que son buenas o el cambio más eficaz. Cuando una terapeuta invita a un cliente a colaborar, la responsabilidad se hace compartida. Hay quienes piensan que los terapeutas que trabajan colaborativamente abdican ingenuamente de su responsabilidad: no es así. Cuando la terapeuta asume la postura filosófica reflexiva, el dualismo y la jerarquía entre terapeuta y cliente colapsan, y la responsabilidad se comparte. En realidad, yo encuentro que en estas condiciones la terapeuta deviene más responsable hacia el cliente. (pp. 149-150) 
A medida que avanzábamos en la supervisión, Camila señalaba que la madre del joven recibió la carta y comenzó a leerla, y mientras la leía la carta comenzaba a emocionarse.

En ese momento pensé que se sentiría cuestionada, o por lo menos creo que eso esperaba ella que yo hiciera, que la cuestionara. Lo que hice fue quedarme tranquila, intentar demostrarle que yo estaba ahí para ella. Conversamos harto después de la lectura, y confirmó lo que su hijo pensaba de la relación que mantenía con el padre de éste. Mi intención en ese momento no fue aconsejarla, aunque quizás algunos pensarían que estuve mal por no decirle que "debería dejara a su pareja (...) pero mi intención era otra, recordé que debía posicionarme siempre desde la colaboración y no desde la imposición, por lo tanto, le consulté qué esperaba ella de esta sesión. Ahí fue donde me dijo que quería responderle esa carta a su hijo. Le pregunté si quería realizarlo en una próxima sesión, pero ella me dijo que no. Necesitaba decirle algunas cosas a Boris, las cuales nunca había pensado en decirle, así que le presté un cuaderno y comenzó a escribir. (González, 2020)

A continuación se muestra un extracto de la carta elaborada por la madre de Boris:

Querido hijo:

Primero que todo, decirte que te amo, te adoro luego de haber leído tu carta, quiero decirte que me alegra que comprendas que cometiste alguno que otro error, todos los cometemos de una u otra forma, ya me he equivocado mil veces (jejeje), lo bueno es que lo comprendas y sigas superándote día a día, yo tengo mucha fe en ti, sé que eres super inteligente, de buenos sentimientos un excelente hombrecito, sobre el tema de tu papá (como ya te había comentado) ya no estará tan seguido por la casa. Se que ello implica un esfuerzo para nosotros, económicamente hablando, pero confío en ustedes y en dios, que todo saldrá bien, quiero pedir tu apoyo en lo que se nos venga por delante, estudia; ya que te hará mucha falta en el futuro, no lo hagas porque yo te reto, hazlo pensando en el porvenir. Se que a veces puedo ser muy pesada pero lo único que quiero es que tanto tú, como tus hermanos sean personas de bien y que sean felices, siempre estaré ahi para ti, sé que cualquier meta que te propongas, lo logra- 
ras, siento que estas viviendo muy de prisa, quisiera que vivas las etapas con calma, disfrutando cada una de ellas, "todo a su tiempo", sé que quieres trabajar, pero eres muy joven aun, créeme que después te aburrirás de trabajar tanto. Mi niño, me gustaría que volvieras a ser chico y no hubieses tenido que pasar malos momentos, me gustaría tenerte en una burbuja y que nada malo te tocase jamás, te pido disculpa por las veces que me he equivocado. La vida no viene con un manual, asi que aprendamos de nuestros errores y yo no soy la excepción, pero te propongo que sigamos aprendiendo juntos, que cuando tu estes cojo yo sea tu apoyo y que cuando yo cojee, se tu mi apoyo. Y sigamos que se puede, juntos, unidos sigue tus metas, lo lograrás. Te ama Mamá.

Es muy interesante centrarnos no solo en aquello que jamás había sido preguntado, sino que también en lo que "no había sido contado", como una forma de facilitar un espacio para que tanto Boris como su madre puedan tener una voz en la intervención. Ambos pueden contar su historia, su dolor, sus anhelos y sus formas de resistencia a la opresión del sistema, rescatando sus propios saberes locales. En este caso, su voz puede ser renarrada y resignificada por ellos y por otros, en la medida en que sean leídas. Para White (2002), en la práctica narrativa las personas que consultan a los terapeutas hacen una contribución significativa a la identificación, desarrollo y refuerzos a los saberes y habilidades apropiados para la práctica terapéutica.

En la siguiente supervisión conversamos acerca de cómo podríamos favorecer la reflexión de Boris respecto a la carta que recibiría. Pensamos en varias estrategias y, luego de un momento, nos dimos cuenta de que era impredecible cómo reaccionaría frente a la lectura, aunque de algo estábamos seguros: había generado un vínculo importante con Camila y eso permitiría poder contener a Boris y acompañarlo en ese momento.

Conversamos también sobre el fenómeno de la violencia intrafamiliar. Desde una perspectiva socio-jurídica es algo que no podíamos pasar por alto, ya que entendemos que las intervenciones se enmarcan en un piso mínimo que es "el respeto por los derechos humanos". Entonces, ¿cómo podíamos ayudar a esa familia, sin que se sintiera más vulnerada? ¿Cómo podíamos devolverles el control de sus vidas? Y eso nos invitó a pensar en una tercera pregunta: ¿es esto importante para 
la comisión de delitos? (situación por la cual llegó el adolescente al programa).

A medida que analizábamos la carta nuestras preguntas se fueron respondiendo, como si la voz de la madre de Boris aún se encontrara junto a nosotros. Al parecer la decisión la había tomado, la carta a su hijo, le permitió desarrollar algo que algunos autores refieren como "relieve dramático"8, o lo que, en palabras de White (2002, p. 246), podría definirse como la narración y re-narración: "La narración y re-narración de las historias de las vidas de las personas, lo que contribuye a la contextualización múltiple de las acciones y eventos de las vidas de las personas con objetivos, valores y temas compartidos, y que es generadora de descripción densa". Sin lugar a dudas, este elemento se constituyó como agente reflexivo para el desarrollo de una nueva narración de la experiencia de la madre, y una forma de pensar el futuro desde una posibilidad distinta.

Durante las sesiones siguientes Camila trabajó con Boris en la lectura de la carta escrita por su madre, elemento que generó diversas sensaciones de bienestar en el adolescente.

Una de las últimas sesiones que tuvo Camila destinadas al trabajo vincular ${ }^{9}$ fue principalmente explorar con el adolescente qué cosas deberían comenzar a trabajar para ajustarse a su causa de derivación al programa, y así cumplir con lo que señala la ley de Responsabilidad Penal Adolescente como tercer principio fundamental: Las sanciones, junto con hacer efectiva la responsabilidad del joven infractor, tienen por objeto realizar un trabajo orientado a la reinserción social de los adolescentes infractores (Ministerio de Justicia, 2007), sin que esto se alejara de los diálogos colaborativos posmodernos. Para lo anterior, el adolescente propuso escribirse una carta a él mismo, por la necesidad de aclarar algunos pensamientos que lo acompañaban desde hace algunas sesiones.

8 Los autores Diclemente y Prochaska aluden al concepto relieve dramático, cómo un proceso en el que las personas se conectan con alguna experiencia de sufrimiento y dolor, significativa para ellos, y que les permite otorgar un significado a su proceso de cambio. Lo anterior facilita el tránsito desde un estadio motivacional pre-contemplativo a uno contemplativo.

9 Entendemos que el trabajo vincular es algo que se mantiene durante toda la intervención, sin embargo, aquí lo planteamos como última sesión, destinada a la apertura. 
A continuación, se muestra un extracto de la carta redactada por Boris, destinada a él mismo:

Querido Boris, quiero decirte que vas muy bien en los estudios, pero que pasa con el vicio debes esforzarte por dejar de fumar más ahora que vas a ser papa tienes que reducir gastos y evitar las tentaciones. Entiende que el dinero sucio fácil se va. Cuida a tu madre que ya no está para pasar rabias yo se que a veces no hay plata pero siempre tienes un plato de comida y no te gustaría que un día roben a alguien de tu familia. No te enojes cuando no tengas para consumir, tu familia no es la culpable sigue esforzándote y no caigas en la tentación, empieza a buscar trabajo.

De esta manera, Boris decide asistir a un programa de tratamiento de consumo de alcohol y drogas llamado "Programa Ambulatorio Intensivo Fernando Aliaga". El adolescente poco a poco comienza a disminuir el consumo de drogas, aunque no finaliza su proceso de tratamiento, ya que en el transcurso del tiempo se entera que va a ser padre, decidiendo así priorizar por el sistema educativo y por acompañar a su pareja en el proceso de embarazo.

\section{Preparación para el final de la intervención o egreso}

Respecto de la supervisión realizada con la delegada, y comprendiendo que a Boris le restaba aún aproximadamente ocho meses de sanción, decidimos mantener una lógica de trabajo que se ajustara a la ética colaborativa, propia de las terapias posestructuralistas posmodernas. Lo anterior permitió que el adolescente se ajustara a los requerimientos que mantenía la ley, ejecutada a través del Tribunal de Garantía perteneciente a la ciudad de Iquique, además del Programa de Libertad Asistida, sin alejarnos de las necesidades no-criminógenas que necesitaba abordar Boris.

En cuanto al espacio de encuentro entre el supervisor y la supervisada, no fue posible finalizar estas intervenciones, dado que son parte de un programa de funcionamiento con el que cuentan los dispositivos de libertad asistida; sin embargo, Camila, , desde la ética colaborativa y como una forma de contar lo que significó para ella el proceso de supervisión, escribió una carta narrándonos su experiencia: 


\section{Estimado Rodrigo}

A veces resulta complejo siquiera imaginar lo que la vida nos tiene preparado. ¿Por qué lo digo? Porque al pensar en los avances, tropiezos y retrocesos siempre se concluye en que todo lo realizado trae consigo un aprendizaje que servirá para pulir en sucesos próximos una acción. De esta manera puedo resumir lo que ha sido mi aprendizaje y desarrollo personal y profesional durante este último tiempo en el quehacer profesional y proceso de intervención. Cuando se tiene un sueño y se lucha por él, se consideran las barreras que pueden surgir, decretando que todo sucederá a nuestro favor; Pero, a medida que avanzamos a lo largo de la vida nos damos cuenta de que no todo es tan fácil, que la vida no es blanco y negro, que existen matices los cuales se deben considerar y no solo eso, sino también respetar. Todos (o casi todos) al comenzar una carrera profesional tenemos tanta alegría como temor por lo que vendrá, pero al pasar los años y encontrarnos con la profesión, con lo que elegimos, con nuestros sueños, vamos aprendiendo que la práctica es lo que le da valor a las cosas y sentido al título, eso es precisamente lo que nos hace mejor frente a los demás. Pero en realidad creo que ello no es lo más importante, lo que, sí lo es, es la confianza, el fiato, la importancia y el valor que nos entregan los usuarios con los que intervenimos, sin lugar a duda eso es el mejor reconocimiento que podemos tener. Lo que nos convierte en un profesional respetado y admirado es el comprender que existen sucesos que marcan la vida de las personas, considerar que cada una es distinta, lo que no significa que sea mejor o peor que la otra; que existen mil y una formas de intervenir, que si creemos que una no sirve, tengamos la convicción que otra sin lugar a duda servirá y que, muchas veces, la menos pensada es la que justamente servirá para generar avances positivos.

Por lo expuesto a través de estas líneas, solo queda mencionar que hasta el momento creo firmemente en la diversidad a la hora de ejercer, lo que plasmo a través del aprendizaje obtenido de la supervisión clinica (por la cual me he sentido más preparada) y la intervención narrativa que he comenzado a practicar con un joven que se encuentra cumpliendo sanción. Gracias a esta técnica hemos logrado avances significativos, los cuales seguimos y seguiremos trabajando, ya que la misma ayuda a comprender, tanto al profesional 
como al adolescente, que el problema es externo a las personas, que los propios pensamientos plasmados en un papel nos refleja que las respuestas a lo que nos aqueja las tienen ellos mismos, las palabras tienen poder, así como a veces suelen generar daño y rencor, también con ellas se puede sanar.

La utilización de la escritura, el lenguaje e inclusive la expresión corporal, es el primer paso hacia el cambio por lo que se quiere lograr. Finalmente, ¿por qué esta técnica en lo personal me ha servido? Porque idealmente posibilita mayor conocimiento y adherencia del adolescente intervenido, pero en la práctica ha hecho que mis intervenciones cobren otro sentido, uno más humano, más real y concreto; ha disminuido la ansiedad frente a lo que vendrá, ha traido sorpresas inesperadas y, sobre todo, me ha dado mayor seguridad a través del agradecimiento muchas veces indirecto del adolescente con el que he podido intervenir. Att. Camila González. (González, 2019)

Lo anterior demuestra la necesidad de establecer una práctica de supervisión clínica que se diferencie de una supervisión de carácter formativa, principalmente porque el profesional supervisado se encarna en el diálogo y en la supervisión, abandonando el rol simbólico de "objeto" o "inerte" frente a la intervención, y en ocasiones visualizado como vertiente para "introducir el conocimiento de quien supervisa". La supervisión clínica desarrolla una postura contraria a la anteriormente descrita, en la que existen dos o más personas conversando sobre otra experiencia, desarrollando conocimiento a través del diálogo, sobre las narraciones y las re-narraciones de las experiencias del consultante, del supervisado y de quien cumple el rol de supervisor, humanizando la relación y desarrollando otras posibilidades de abordaje.

\section{Reflexiones y consideraciones finales}

Durante el transcurso de este documento, hemos podido transitar desde una epistemología estructuralista de las terapias, hacia un enfoque postestructuralista, situado desde una ética dialógica colaborativa. El vaivén entre el constructivismo social de la Terapia Narrativa de White y Epston y el construccionismo radical, como lo definirían Gergen, Anderson y Goolishian, permite que los procesos de terapia sean comprendidos como una acción conversacional, a través del lenguaje y situados en un contexto histórico más amplio. Ambas visiones poseen 
un punto de encuentro y es el total cuestionamiento a las pretensiones de verdad universal. En concordancia con lo anterior, White (2002) señala lo siguiente:

La cultura de la psicoterapia es una cultura de discursos profesionales. Estos discursos profesionales están caracterizados por clases de conocimiento que tienen pretensiones de "verdad" sobre la condición humana: pretensiones que se adscriben el estatus de realidad objetiva y que se consideran universales, y se ocuparán de "hechos" referidos a la naturaleza de la vida que pueden encontrarse en todas las personas, sin consideración de la cultura, la circunstancia, el lugar, la época y demás. (p. 155)

La supervisión clínica, desde una posición posmoderna, comprende que las personas "somos fabricantes de historias. Narramos para darle sentido a nuestras vidas, para comprender lo extraño de nuestra condición humana" (Bruner, 2013), así como también comprende que los saberes de los terapeutas se encuentran principalmente nutridos de sus experiencias totales acumuladas. El problema de lo anterior, no son las "experiencias de los terapeutas", sino los efectos que generan al ponerse en juego durante un contexto de intervención, en una posición que solo cuenta con un sitial privilegiado: "el poder del profesional".

La construcción social y la práctica profesional han demostrado ser dos amigas muy cercanos, como la gasolina y el motor de un gran auto de carreras. "Una cosa es generar ideas atractivas, pero la cuestión más importante es si hay o no una relación productiva entre las palabras y los estilos de vida" (Gergen y Gergen, 2011). Los espacios de supervisión desarrollados bajo el lente colaborativo han permitido reflexionar y cuestionar aquellas ideas de control social, construidas culturalmente como "un elemento que favorece el cambio de las personas" en los procesos de intervención instalados en el campo socio-jurídico. De acuerdo con lo anterior, Gergen (2006) refiere:

Una vez que la conciencia de la construcción se instala en ti, es difícil permanecer pasivo. Por ejemplo, cuando te das cuenta de que todo lo que tomamos como verdadero, racional y bueno es así únicamente en función de las conversaciones, empiezas a hacerte preguntas de una trascendencia inquietante. ¿Por qué deberíamos 
aceptar aquello que la tradición nos ofrece? ¿Qué nos estamos perdiendo? ¿ Somos capaces de reconstruir? ¿Mejorarían las cosas? Las preguntas son provocadoras; las repercusiones, infinitas. (p. 53)

La dinámica de supervisión realizada nos permitió instalar en nuestras pretensiones la construcción social. Desde esta posición, no fue posible estancarnos en las explicaciones construidas bajo una dinámica relacional "causa-efecto", y con esto no quiero decir que los estudios de la ciencia no presenten validez, pues claramente la tienen, sino que más bien nos permitió ampliar el horizonte de posibilidades, destacando los saberes locales de las personas como una forma de abandonar las descripciones magras y construir descripciones densas (White, 2002).

Los terapeutas que participan de estos procesos de supervisión lo hacen por distintas circunstancias, principalmente por necesidades profesionales, exigencias de los sistemas laborales, temores o nuevos desafíos, e incluso porque se encuentran sufriendo el conocido término "burnout". En resonancia con lo anterior, White (2002) hace referencia a la supervisión y sus efectos desde un enfoque narrativo:

En este espacio, los terapeutas tienen la oportunidad de comunicar su experiencia de diversos acontecimientos de su trabajo, de hablar de los significados que han sido atribuidos a esos acontecimientos y de explorar los efectos reales de estas experiencias y significados en cuanto a moldear su trabajo y, de manera más general, sus vidas. En el curso de estas conversaciones, las conclusiones magras que los terapeutas suscriben acerca de su trabajo e identidad son deconstruidas. (pp. 191-192)

El proceso de intervención centrado en una ética colaborativa y desarrollado de acuerdo con las prácticas narrativas, permitió que la profesional supervisada pudiera cuestionarse los métodos de intervención comúnmente utilizados, cuestionarse también las pretensiones de "verdades universales" y desarrollar una intervención a la que ella define como "más humana". De igual manera, logró romper con el ciclo de agotamiento (traducido en frustraciones constantes), desarrollando mayor motivación, disminuyendo la ansiedad que generan otros estilos de supervisiones y refundando lo que venía desarrollan- 
do como "intervenciones del trabajo social", reencantándose así con la práctica disciplinar.

Es importante concluir además que durante la supervisión abandonamos los conceptos de "problemas" y "soluciones", escribiéndolos ambos entre comillas, principalmente porque no creemos que hablar de una categoría o de otra sea útil. En la supervisión dialógica colaborativa hablamos de dilema o situación vital como formas de romper el discurso monológico instalado en los significados de "problemas" y "soluciones" al interior del mundo de la terapia. En la terapia, un problema es un asunto para tratar en un discurso, los significados atribuidos son solo realidades creadas socialmente y sostenidas por conductas mutuamente coordinadas en el lenguaje. Para Anderson (2012), "una definición de problema es una posición que alguien toma. Es un sentido que alguien atribuye, una narrativa que alguien ha desarrollado" (p. 114). Por lo tanto, la supervisión clínica presentó como tarea principal llevar la conversación a un lenguaje en el cual el problema ya no existiera.

Otro elemento interesante fue adoptar la postura de no saber, ya que la profesional supervisada, al intentar romper con el concepto de "dominio" al interior de las sesiones, adoptó una posición de estar desinformada, en otras palabras, de no saber. El no saber implica necesariamente humildad, ya que el terapeuta se interesa en aprender lo que la persona tiene que contar, en vez de buscar, exponer, validar o promover su propio conocimiento o interés. De esta manera, Boris logró encontrar en Camila a una persona interesada en conocer su historia, y capaz de generar un clima de respeto frente a sus experiencias de vida.

Ambos profesionales logramos, trabajando de manera colaborativa, centrarnos en Boris y su familia, en sus historias, en sus deseos y en sus motivaciones. Lo anterior no solo puede traducirse como una práctica posmoderna, sino que también como una práctica enmarcada en los derechos humanos, simbolizados éstos como un cascarón que recubre todo el proceso de intervención.

Haber desarrollado una práctica de co-visión alternativa, en la cual se involucraron cuatro personas (supervisor, terapeuta, consultante y madre del consultante), también permitió crear distintas narrativas respecto de una misma historia. Las ideas y las acciones para 
continuar en el proceso de intervención no nacieron en una conversación que dejara de lado los intereses de Boris y su madre, sino todo lo contario, ya que los principales guías que condujeron la exploración de sus vidas fueron ellos. Lo anterior permitió agrandar el océano de posibilidades y, claramente, erradicar lo que en un inicio se había construido como única posibilidad en el discurso profesional: el quebrantamiento de la sanción.

Un punto que no puede ni debe ser invisibilizado en esta conclusión es la necesidad de desarrollar un Trabajo Social Clínico al interior de los programas de intervención con jóvenes que han conflictuado con el sistema judicial y, en general, dentro de la red de instituciones que pertenecen al Servicio Nacional de Menores. El ejercicio de la clínica del Trabajo Social ha sido una necesidad que no solo busca validar un trabajo que se viene realizando hace bastantes años en estos programas de intervención, sino que también permitiría regularizar y profundizar sobre aquel conocimiento que debería manejar un trabajador social que realiza intervención socio-jurídica con familias. Lo anterior es una analogía que se desprende no solo de esta experiencia de intervención, puesto que viene a reafirmar aquello escrito por Hamilton (1967), quien refiere que "el término psicoterapia no es sinónimo de psicoanálisis, ni es un arte o ciencia exclusiva del psiquiatra con formación médica" (p. 14), comprendiendo así que la psicoterapia es un ejercicio de carácter transdisciplinar y, por lo tanto, requiere de programas de formación adicional a los cuales el trabajador social debe acceder en Chile, pese a que existen programas en los cuales se pueden formar los profesionales del Trabajo Social, esta oferta debe ser masificada.

El Trabajo Social Clínico requiere de una especialización, la cual no solo permite profundizar en el conocimiento del terapeuta que lo ejerce, sino también aliviar el dolor humano. Con relación a lo anterior, Hamilton (1967) sostiene que "la personalidad no es sólo una unidad psicosomática, sino también psicosocial” (p. 14). Esta aseveración se encuentra en total concordancia con el ejercicio de la clínica del Trabajo Social que se desarrolla en el campo de la intervención infanto/adolescente, donde su principal labor es acompañar a la persona en la reparación y la restauración de los derechos que han sido vulnerados, la responsabilización frente a la vulneración de derechos 
a terceras personas y la reinserción social, elementos que, en su conjunto, presentan un fin más amplio: aliviar el malestar psicosocial. (Reyes y Díaz, 2017)

Creo importante mencionar que la clínica en contextos socio-jurídicos en familia, parte de la base de que los tiempos psicosociales y los tiempos judiciales son diametralmente opuestos, caminando ambos por veredas distintas. La labor profesional en estos espacios se encuentra constantemente centrada en la resolución de esta tensión ética, así como de otras que aparecen en la medida en que se recorre el camino imaginario de la intervención. Finalmente, no quisiera que se quedara en la retina de los lectores la creencia de que esta es la "única forma" o "forma correcta" de realizar una supervisión clínica, pues existen diversas metodologías para realizarla. En lo personal, la supervisión clínica desde la ética colaborativa posmoderna, al alero de las prácticas narrativas y los equipos de reflexión, es la que más se ajusta a mis principios y valores profesionales hoy, considerándola en sintonía con el principio de justicia social que declaró en 2018 la Federación Internacional de Trabajo Social.

\section{Referencias}

Alarcón, F. E. y Schaefer, H. (2015). Manual de técnicas de psicoterapia breve. Aportes desde la terapia sistémica. Santiago, Chile: Editorial Mediterráneo Ltda.

Andersen, T. (1991). The reflecting Team. Dialogues and Dialogues About Dialogues. New York, Estados Unidos: W.W. Norton and Company, New York, London.

Anderson, H. (1997). Conversation, Lenguage, and Possibilities. A Postmodern Approach to Therapy. Buenos Aires: Amorrortu editores.

Bateson, G. (1976). Pasos para una ecología de la mente. Buenos Aires: Carlos Lohlé.

Bateson, G. (1993). Espíritu y naturaleza. Buenos Aires: Amorrortu.

Berger, P. L. y Luckman, T. (1969). La construcción social de la realidad. Buenos Aires: Amorrortu.

Boscolo, L., Cecchin, G., Hoffman, L. y Penn, P. (2003). Terapia familiar sistémica de Milán. Diálogos sobre teoría y práctica. Buenos Aires: Amorrortu. 
Braithwaite, J. (1981). The Myth of Social Class and Criminality Reconsidered. American Sociological Review, 36-57.

Bruner, J. (2013). La fábrica de historias. Derecho, literatura, vida. Buenos Aires: Fondo de Cultura Económica.

Bustillos, G. y Vargas, L. (2001). Técnicas participativas para la educación popular. Santiago, Chile: CIDE.

Bustos, A. (2014). Modelos contemporaneos de intervención en trabajo social: Revisión bibliográfica del modelo narrativo. Perspectivas, 67-83.

Corporación Opción. (2015). Sistema Integrado de Evaluación Diferenciada para Adolescentes y Jóvenes SIED-AJ. Santiago, Chile: Corporación Opción.

Dallorso, N. (2000). Comentarios a Jacques Danzelot: la policía de las familias. Delito y Sociedad, 167-170.

Derrida, J. y Caputo, J. D. (2009). La deconstrucción en una cáscara de nuez. Buenos Aires: Prometeo Libros.

Dorfman, R. (1996). Clinical Social Work: Definition, Practice and Vision. United States: Brunner/ Mazel.

Fernandez, E., London, S. y Tarragona, M. (2015). Las conversaciones reflexivas en el trabajo clínico, el entrenamiento y la supervisión. México: Grupo Campos Elíseos.

Friedman, S. (2005). Terapia familiar con equipo de reflexión. Una práctica de colaboración. Buenos Aires: Amorrortu editores.

Gergen, K. (1994). Realities and relationships: sounding in social construction. Cambridge: Harvard University Press.

Gergen, K. (2006). Construir la realidad. El futuro de la psicoterapia. Barcelona: Paidós.

Gergen, K. J. y Gergen, M. (2011). Reflexiones sobre la construcción social. Madrid: Paidós.

Hamilton, G. (1967). Psicoterapia y orientación infantil. Buenos Aires: Paidós.

Hoffman, L. (1981). Foundations of family therapy. A conceptual framework for systems change. Nueva York: Basic Books.

Ituarte, A. (2002). El acontecer clínico en Trabajo Social. "La supervisión clínica en Trabajo Social". Trabajo social hoy, 42-60.

Ituarte, A. (2012). Una reflexión sobre los modelos de intervención de los trabajadores sociales desde la experiencia de supervisión. En 
E. Sobremonte, Epistemología, teoría y modelos de intervención en trabajo social reflexión sobre la reflexión disciplinar en España (pp. 191.204). Bilbao: Universidad de Deusto.

Ituarte, A. (2017). Prácticas del Trabajo Social Clínico. Valencia: Nau Llibres.

Ministerio de Justicia. (2007). Ley de Responsabilidad Penal Adolescente. Santiago: Biblioteca del Congreso Nacional de Chile.

Linares, J. L., Putbill, M. j. y Ramos, R. (2005). Las cartas terapéuticas. Una técnica narrativa en terapia familiar. Barcelona: Herder.

London, S. y Rodríguez, I. (2000). La supervisión como grupos de conversaciones colaborativas. Grupo Campos Elíseos, 1-8.

Pakman, M. (1997). Micro-política de clase social en la vida familiar: la terapia como práctica social crítica. Systémica: Revista de la Asociación Andaluza de terapia familiar y sistemas humanos, 69-80.

Raffo, H. Á., Iglesias, A. M., Gamas, R. E. y Sánchez, R. E. (2000). Menores infractores y libertad asistida (Los cinco puntos). Buenos Aires: La Roca.

Ramos, R. (2015). Terapia narrativa con familias multiproblemáticas. Madrid: Morata.

Reyes, D. y Díaz, M. (2017). El lugar de la práctica clínica sistémica en el Trabajo Social: Un ensayo crítico sobre la experiencia profesional de dos trabajadores sociales en un Programa de Reparación en Maltrato Grave y Abuso Sexual. Revista de Trabajo Social de la Universidad de Concepción, 16, 63-77.

Ruesch, J. y Bateson, G. (1965). Comunicación: La matriz social de la psiquiatría. Buenos Aires: Paidós.

Satir, V. (1983). Satir step by step. A guide to Creating Change in Families. California, Palo Alto, California: Science and Behavior Books, Inc.

Satir, V. (2006). Peoplemaking: El arte de crear una familia. Barcelona: RBA Libros S.A.

Servicio Nacional de Menores. (2017). Orientaciones Técnicas - Programa de Libertad Asistida. Santiago, Chile: Servicio Nacional de Menores.

Soler, R. C. (2018). Justicia juvenil y prácticas restaurativas. Trazos para el diseño de programas y para su implementación. Madrid: NED ediciones. 
Szasz, T. (2008). El mito de la enfermedad mental. Bases para una teoría de la conducta personal. Buenos Aires: Amorrortu.

Szmulewicz, T. (2013). La persona del terapeuta: Eje fundamental de todo proceso terapéutico. Revista chilena de neuro-psiquiatría, 61-69.

Tarragona, M. (2013). Psicología positiva y terapias constructivas: Una propuesta integradora. Terapia Psicológica, 115-125.

Valenzuela, J. E. (2014). El origen del paradigma de riesgo. Polít. crim., 9(17) Art. 3, 58-117.

White, M. (2002). El enfoque narrativo en la experiencia de los terapeutas. Barcelona: Gedisa.

White, M. (2002). Reescribir la vida: entrevistas y ensayos. Barcelona: Gedisa.

White, M. y Epston, D. (2008). Medios Narrativos para fines terapéuticos. Barcelona: Paidós.

Referencias electrónicas

Corporación Opción (s/f). Somos. Recuperado de https://opcion.cl/ somos/mision/

Federación Internacional de Trabajadores Sociales (2018). Definición Global del Trabajo Social. Recuperado de https://www.ifsw. org/what-is-social-work/global-definition-of-social-work/ definicion-global-del-trabajo-social/ 